\title{
PERANCANGAN SISTEM PENGHITUNG JUMLAH KENDARAAN PADA AREA PARKIR DENGAN METODE BACKGROUND SUBTRACTION BERBASIS INTERNET OF THINGS
}

\author{
Monica Sari Hariyanto*), Aghus Sofwan, dan Achmad Hidayatno \\ Departemen Teknik Elektro, Universitas Diponegoro \\ Jl. Prof. Sudharto, SH, Kampus UNDIP Tembalang, Semarang 50275, Indonesia \\ ${ }^{*}$ E-mail: monicasari57@ @ @mail.com
}

\begin{abstract}
Abstrak
Kemajuan teknologi yang berkembang pesat dan semakin meluas saat ini tidak dapat dicegah. Hal ini sejalan dengan perkembangan penggunaan internet untuk mencakup kebuutuhan sehari hari. Salah satu implementasi yang berkembang di masyarakat ialah aplikasi smart city. Dalam konsep pengembangan yang lebih kecil, smart city dapat di terapkan pada sebuah kampus guna memudahkan sistem manajemen kampus yang disebut smart campus atau kampus pintar. Smart campus memiliki berbagai macam fitur yang diterapkan, salah satunya smart open parkir. Fitur tersebut digunakan untuk menganalisa jumlah kendaraan yang keluar masuk pada area parkir terbuka di sekitar kampus. Masalah yang sedang dihadapi pada area parkir tebuka adalah sistem penghitungan jumlah kendaraan yang terparkir yang masih dilakukan secara manual, sehingga masyarakat kampus kesulitan untuk menentukan tempat parkir kendaraannya. Dalam penelitian ini dirancang suatu sistem yang dapat menghitung jumlah kendaraan yang melintasi area parkir tebuka. Masukan sistem berupa video yang diperoleh dari kamera. Metode deteksi gerakan yang digunakan adalah background subtraction dengan algoritma gaussian mixture model. Sistem ini menggunakan Raspberry Pi sebagai komputer mini yang diaktifkan dengan pemberian catu daya yang bersumber dari panel surya. Adanya raspberry pi beserta komponen-komponen pelengkapnya seperti kamera sebagai media pengambilan video yang dimonitoring secara otomatis merupakan ciri dari IoT.
\end{abstract}

Kata kunci: background subtraction, Raspberry Pi, Internet of Things

\begin{abstract}
Technological advances are growing rapidly and are increasingly widespread at this time can not be prevented. This is in accordance with the development of internet usage for daily needs. One implementation that has developed in the community is the smart city application. In a smaller development concept, smart city can be applied to a campus to facilitate the campus management system called smart campus or smart campus. Smart campus has a variety of features that can be applied, one of them is smart open parking. This feature is used to analyze the number of vehicles in and out of the open parking area around the campus. The problem that is often encountered in the open parking area is the system of calculating the number of parked vehicles that are still done manually, so that the campus community has difficulty determining the parking space of the vehicle. In this study a system that can calculate the number of vehicles that cross the open parking area is designed. Input system is a videos obtained from the camera. The motion detection method used is background subtraction with a gaussian mixture model algorithm. This system uses Raspberry Pi as a mini computer that is activated by providing a power supply sourced from solar panels. The presence of raspberry pi and its complementary components such as a camera as a video monitoring media that is automatically monitored is a feature of IoT.
\end{abstract}

Keywords : background subtraction, Raspberry Pi, Internet of Things

\section{Pendahuluan}

Kemajuan teknologi yang terus berkembang dengan pesat saat ini membuat banyak macam program untuk membantu mengembangkan produk berbasis Internet of Things (IoT). Salah satu contoh bentuk pengembangan produk berbasis Internet of Things (IoT) ialah smart city. Smart city didefinisikan sebagai sebuah konsep pengembangan dan pengelolaan kota dengan pemanfaatan teknologi informasi dan komunikasi (TIK) untuk menghubungkan, memonitor, dan mengendalikan berbagai sumber daya yang ada di dalam kota dengan lebih efektif dan efisien untuk memaksimalkan pelayanan kepada warganya serta mendukung pembangunan yang berkelanjutan [1].

Dalam konsep pengembangan teknologi yang lebih kecil, smart city dapat diterapkan di dalam sebuah kampus yang disebut smart campus atau kampus pintar. Smart campus 
merupakan sebuah konsep kampus yang menerapkan dan memadukan sistem pembelajaran, manajemen kampus, perpustakaan dan lain sebagainya dengan penggunaan teknologi informasi. Salah satu fitur yang ditawarkan dari smart campus adalah smart open parking. Fitur tersebut digunakan untuk menganalisa jumlah kendaraan yang keluar masuk pada area parkir terbuka di sekitar kampus. Konsep dari smart campus adalah intergrasi data ke internet dan akses data dari internet, berbasis reporting maupun update feed. Updating data tersebut bisa berasal dari informasi yang diberikan oleh masyarakat maupun perangkat mesin otonom melalui komunikasi internet dalam arsitektur Internet of Things (IoT). Arsitektur ini memungkinkan updating informasi secara real time dari berbagai lokasi dengan menggunakan koneksi internet.

Terdapat beberapa Penelitian yang telah dilakukan sebelumnnya mengenai sistem pendeteksi objek. F. A. Surur [2] merancang sistem pengolahan citra yang diterapkan pada proses pendeteksian kendaraan dengan menggunakan salah satu metode pengolahan citra yaitu metode gaussian mixture model yang digunakan untuk menghitung traffic jumlah kendaraan yang melintasi jalan yang terekam pada kamera. Da Li, dkk[3] dan Wen-Jun Wang, dkk[4] merancang sistem yang dapat mendeteksi dan menghitung kendaraan menggunakan metode background subtraction dengan OpenCV. Metode tersebut cukup baik bila diterapkan untuk mendeteksi objek bergerak dengan latar diam, namun kurang akurat untuk mendeteksi objek bergerak bila pada latar terdapat gerakan atau derau. M. Harry Bintang [5] merancang aplikasi deteksi gerakan manusia yang terekam pada kamera keamanan menggunakan metode abackground subtraction dengan algoritma gaussian mixture model.

Pada Penelitian ini merancang sebuah sistem dalam fitur smart campus yaitu smart open parking yang diterapkan di Universitas Diponegoro. Masukan yang digunakan adalah sebuah video yang diambil menggunakan kamera digital yang ditempatkan di pintu masuk area parkir terbuka. Penghitungan jumlah kendaraan yang lewat diklasifikasikan menjadi dua jenis kendaraan yaitu mobil dan motor yang dilakukan dengan menggunakan metode background subtraction. Proses deteksi objek bergerak dengan metode background subtraction didasarkan pada perbedaan antara background referensi dengan frame. Hasil yang diperoleh dari sistem ini adalah pemberitahuan mengenai jumlah kendaraan yang terparkir pada area parkir, guna memudahkan pengguna untuk mencari area parkir yang tersedia di wilayah Universitas Diponegoro.

\section{Metode}

\subsection{Blok Diagram Sistem}

Sistem yang dirancang adalah sebuah alat untuk mendeteksi jumlah kendaraan yang keluar masuk area parkir Departemen Teknik Elektro UNDIP dengan mengklasifikasikan dua jenis kendaraan yaitu mobil dan motor. Deteksi trafik yang diterapkan memakai metode background subtraction dengan algoritma gaussian mixture model (GMM), fokus penelitian pada perbandingan laju pembelajaran (learning rate) dan perbandingan region of interest (ROI). Kamera mendeteksi adanya gerakan pada region of interest (ROI). Setiap kendaraan yang melewati ROI kemudian dihitung jumlahnya. Blok diagram dapat dilihat pada Gambar 1. Hasil dari proses perhitungan masuk ke log dalam ekstensi .txt. Selain masuk ke $\log$, hasil dari proses perhitungan diunggah ke basis data di internet.

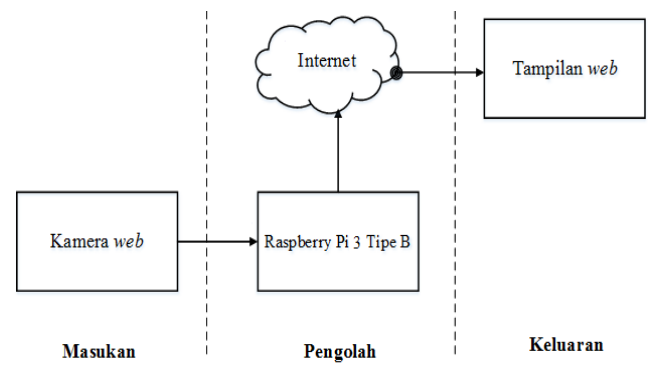

Gambar 1. Blok diagram sistem

\subsection{Bagian Masukan}

Kamera akan merekam keadaan suatu lokasi lalu mengirimkan rekaman tersebut ke Raspberry Pi. Kamera web ini memiliki port keluaran berupa USB (Universal Serial Bus) yang disambungkan ke Raspberry Pi.

\subsection{Bagian Pengolah}

Raspberry Pi adalah komponen yang bertanggung jawab sebagai pengolah [6]. Blok pengolah ini melakukan lima proses, yakni proses deteksi kendaraan, klasifikasi jenis kendaraan, penghitung jumlah kendaraan, log kendaraan, dan sinkronisasi data. Video yang direkam kamera kemudian akan diproses pertama kali oleh pendeteksi gerak kendaraan. Jika gerak kendaraan yang dideteksi masuk ke dalam Region of Interest (ROI) maka counter akan mencatat hitungan jumlah kendaraan. Terdapat 2 wilayah perhitungan yang digunakan dalam sistem, yaitu wilayah untuk mendeteksi kendaraan masuk (+) dan keluar(-).

\subsubsection{Proses Deteksi Gerak}

Proses deteksi gerak berfungsi untuk mendeteksi objek bergerak dari video yang direkam oleh kamera. Deteksi gerak menggunakan fungsi yang terdapat pada library OpenCV, melalui API (Application Programming Interface) $\mathrm{C}++$ bernama cv2.BackgroundSubtractorMOG [7]. Fungsi tersebut memiliki parameter diantaranya history, varThreshold, dan bShadowDetection. Parameter history berfungsi untuk menetapkan jumlah frame terakhir yang memengaruhi model latar belakang. Parameter varThreshold berfungsi untuk mengatur nilai ambang pada 
background subtraction. Parameter bShadowDetection berfungsi untuk mendeteksi bayangan pada video. Parameter lain yang harus diatur, yakni learningRate. Parameter learningRate mengatur nilai laju pembelajaran yang akan digunakan. Pada perancangan ini, parameter learningRate akan diatur sesuai dengan kondisi lingkungan. Nilai parameter learningRate pada kondisi lingkungan sistem akan ditentukan dari hasil pengujian variasi parameter learningRate.

\subsubsection{Proses Klasifikasi Jenis Kendaraan}

Proses klasifikasi jenis kendaraan digunakan untuk membedakaan jenis kendaraan yang terdeteksi mobil atau motor. Klasifikasi jenis kendaraan menggunakan data koordinat nilai tinggi dan data koordinat nilai lebar untuk menentukan ukuran kendaraan yang terdeteksi oleh sistem.

\subsubsection{Proses Penghitung Jumlah Kendaraan}

Proses penghitung jumlah kendaraan menggunakan sistem ROI (Region of Interest). Ada dua ROI yang digunakan dalam sistem ini, yaitu ROI untuk mendeteksi kendaraan yang masuk dan ROI untuk mendeteksi kendaraan yang keluar area parkir tebuka. Jika centroid pada bounding box masuk ke dalam ROI, maka kendaraan dihitung 1 sebagai kendaraan masuk dan -1 untuk kendaran yang keluar. Centroid yang sama akan dideteksi tiap framenya untuk menghindari kendaraan dihitung berkali-kali.

\subsubsection{Proses Log Kendaraan}

Proses $\log$ kendaraan menggunakan library datetimeuntuk dapat beroprasi. Proses pertama $\log$ kendaraan yaitu dengan mengatur waktu data masuk log. Waktu diinisialisasi dalam variabel waktu_lalu dan waktu_skrg. Jika nilai pada variabel waktu_skrg habis dibagi 30 (30 detik) maka data akan dikirim ke bagian pengiriman basis data dan dicatat datanya dalam log. Penghitung juga akan diatur ulang menjadi $0($ counter $=0)$ setelah 30 detik.

\subsubsection{Proses Sinkronisasi Data}

Proses pengirirman data dalam sistem dijalankan oleh file PHP di internet [8]. Proses yang berlangsung pada Raspberry Pi adalah untuk sinkronisasi antara file PHP dengan program python. Data yang disimpan dalam variabel counter akan dilanjutkan ke sinkronisasi data pada file php setelah 30 detik.

\subsection{Bagian Keluaran}

Bagian keluaran berupa tampilan web yang dirancang dengan HTML dan PHP. File HTML sebagai tampilan web, sedangkan file PHP sebagai koneksi antara basis data dengan tampilan web. Basis data dibuat dengan menggunakan PHPMyAdmin pada dstp.puskom.undip.ac.id.

\subsection{Bagian Penghubung Basis Data dengan Python}

Bagian penghubung antara basis data dengan Python dirancang agar komputasi pada Raspberry Pi tidak berat. Bagian ini merupakan berkas PHP dengan nama cek2.php. Berkas cek2.php berisi queryuntuk memasukkan data ke basis data.

\subsection{Bagian Penghubung Basis Data dengan Python}

Bagian penghubung antara basis data dengan Python dirancang agar komputasi pada Raspberry Pi tidak berat. Bagian ini merupakan berkas PHP dengan nama cek.php. Berkas cek.php berisi query untuk memasukkan data ke basis data.

\subsection{Perancangan Perangkat Lunak}

Diagram alir pengujian deteksi ditunjukkan pada Gambar 2. Tahap pertama adalah ada masukan berupa video. Masukan video kemudian melewati proses background subtraction. Masukan video yang telah melalui proses background subtraction kemudian menentukan laju pembelajaran yang digunakan. Setelahnya, maka kendaraan telah terdeteksi. Proses selanjutnya adalah perhitungan jumlah kendaraan. Dalam perhitungan jumlah kendaraan Region of Interest (ROI) diterapkan dalam frame. Hasil dari kendaraan yang terdeteksi tiap frame ditambah dengan bounding box dan centroid. Setiap centroid menyentuh ROI maka kendaraan dihitung satu $($ counter +1$)$.

Proses selanjutnya adalah masuk pada decision, jika sisa bagi waktu dengan 30 (menandakan 30 detik) adalah nol, maka alur sistem berlanjut ke proses sinkronisasi basis data. Jika sisa bagi bukan nol, maka sistem kembali ke penerapan background subtraction ditunjukkan pada Gambar 3. Proses sinkronisasi basis data dilanjutkan ke pencatatan $\log$ jumlah kendaraan tiap 5 detik. Setelah $\log$ dicatat maka perhitungan jumlah kendaraan diatur kembali menjadi nol (counter $=0$ ). Terdapat decision setelah atur ulang jumlah kendaraan, yaitu break. Tombol untuk melakukan break pada kibor adalah 'Q' yang akan menghentikan program sehingga alur selesai. Jika tombol tidak ditekan maka alur akan diulang dari penerapan background subtraction. 


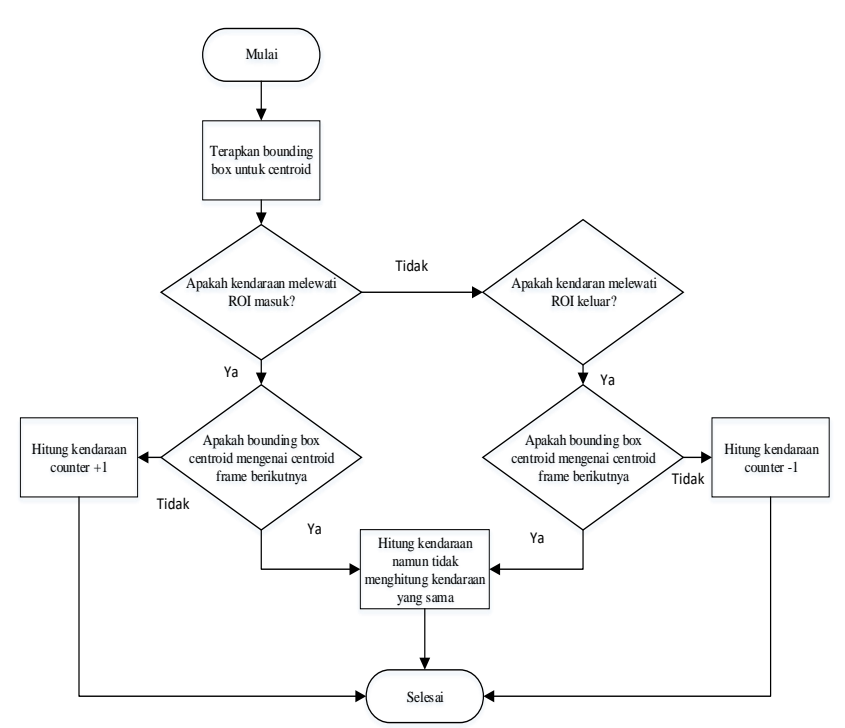

Gambar 2. Diagram alir fungsi pengolah data

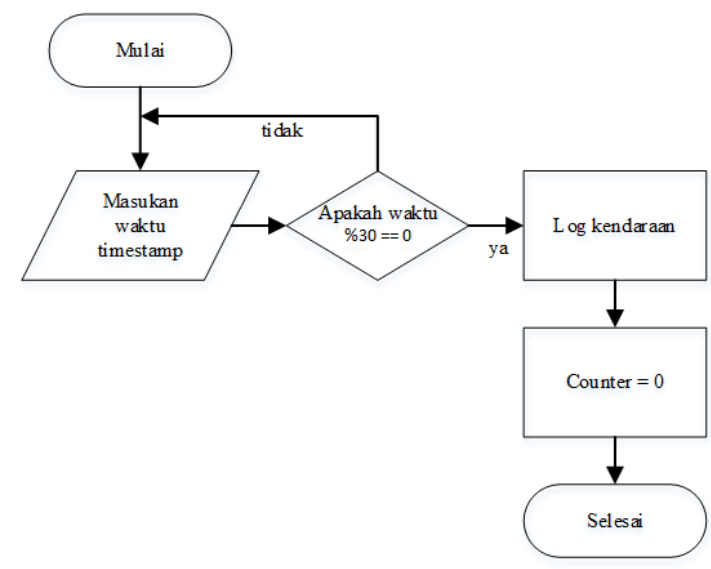

Gambar 3. Diagram alir fungsi $\log$ kendaraan

\subsection{Perancangan Perangkat Keras}

Pada rangkaian alat, Raspberry Pi diberi catu daya yang bersumber dari panel surya yang dihubungkan dengan baterai dan disambungkan pada kamera . Perangkat keras yang telah dirangkai tersebut perlu dipasang pada sebuah tiang tempat pengambilan data, agar titik pengambilan video dapat lebih tinggi dan area jalan yang terekam dapat terlihat dengan jelas. . Perangkat keras yang sudah dirangkai pada tiang ditunjukkan pada Gambar 4.

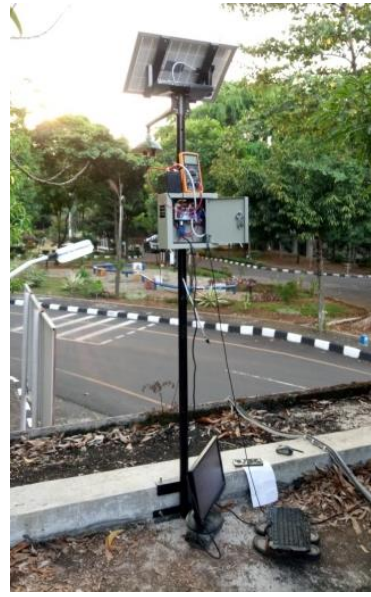

Gambar 4. Rangkaian keseluruhan alat

\section{Hasil dan Analisis}

Masukan yang digunakan adalah video dengan durasi berbeda yang direkam dengan laju frame sebanyak 24 frame per detik. Posisi kamera tidak berubah pada berbagai pengujian. Seluruh pengujian dilakukan pada pagi pukul 08.00 sampai pukul 21.00. Hasil dari pengujian digunakan untuk menghitung tingkat keberhasilan dengan rumus $100 \%-\left(\frac{\text { Selisih }}{\text { Jumlah hitung manual }}\right)$. Pengujian yang dilakukan dengan variasi beberapa parameter, yaitu:

1. Laju Pembelajaran

2. Region of Interest (ROI).

Program yang dirancang menggunakan metode .bashrcuntuk membuat sistem autostart. Bashrc adalah berkasyang mengatur tampilan serta beberapa perintah dari console terminal. Pada berkas bashrc perintah untuk menjalankan program dimasukkan. Apabila perintah sudah dimasukkan ke dalam berkas bashrc, maka perintah tersebut akan langsung dieksekusi oleh sistem sesaat setelah perangkat Raspberry Pi dinyalakan.

\subsection{Pengujian Deteksi Gerak}

Pengujian deteksi gerak bertujuan untuk mencari parameter laju pembelajaran yang sesuai untuk diterapkan pada kondisi lingkunngan sistem. Nilai laju pembelajaran ditentukan berdasarkan riwayat frame. Terdapat 4 variasi riwayat frame yang akan digunakan, yakni 100 frame, 200 frame, 300 frame, dan 400 frame. Sehingga variasi nilai laju pembelajaran yang akan digunakan adalah:

1. Riwayat frame $=100$

Laju pembelajaran $=\frac{1}{\text { riwayat } \text { frame }}=\frac{1}{100}=0,01$

2. Riwayat frame $=200$

Laju pembelajaran $=\frac{1}{\text { riwayat } \text { frame }}=\frac{1}{200}=0,005$

3. Riwayat frame $=300$

Laju pembelajaran $=\frac{1}{\text { riwayat } \text { frame }}=\frac{1}{300}=0,0033$

4. Riwayat frame $=400$ 
TRANSIENT, VOL. 7, NO. 3, SEPTEMBER 2018, ISSN: 2302-9927, 779

Laju pembelajaran $=\frac{1}{\text { riwayat } \text { frame }}=\frac{1}{400}=0,0025$

\subsubsection{Pengujian Variasi Laju Pembelajaran}

Tabel 1. Hasil pengujian deteksi gerak dengan parameter laju pembelajaran
Tabel 2. Hasil pengujian pengaruh variasi laju pembelajaran dengan jumlah frame yang diproses.

\begin{tabular}{|c|c|c|c|c|c|}
\hline \multirow{2}{*}{$\begin{array}{l}\text { Waktu } \\
\text { (detik) }\end{array}$} & \multirow{2}{*}{$\begin{array}{c}\text { Masukan } \\
\text { (jumlah } \\
\text { frame) }\end{array}$} & \multicolumn{4}{|c|}{$\begin{array}{c}\text { Keluaran (jumlah frame tiap variasi laju } \\
\text { pembelajaran) }\end{array}$} \\
\hline & & 0.01 & 0.005 & 0.0033 & 0.0025 \\
\hline 4 & 96 & 39 & 73 & 90 & 91 \\
\hline 8 & 192 & 53 & 89 & 118 & 155 \\
\hline 12 & 288 & 61 & 91 & 130 & 168 \\
\hline 16 & 384 & 70 & 105 & 159 & 191 \\
\hline 20 & 480 & 97 & 118 & 176 & 215 \\
\hline 24 & 576 & 106 & 152 & 201 & 225 \\
\hline
\end{tabular}

Berdasarkan Tabel 2., Selama 24 detik, frame masukan yang akan diproses sebanyak 576 frame. Laju pembelajaran yang berbeda menghasilkan frame keluaran dengan jumlah yang berbeda. Pada laju pembelajaran 0,01 , menghasilkan 106 frame. Laju pembelajaran 0,005, menghasilkan 152 frame. Laju pembelajaran 0,0033, menghasilkan 201 frame. Laju pembelajaran 0,0025, menghasilkan 225 frame. Pada awal waktu, sudah terdapat perbedaan jumlah frame keluaran yang jelas dari masingmasing parameter laju pembelajaran. Pada detik ke-4, laju pembelajaran 0,01 menghasilkan 28 frame. Jumlah tersebut merupakan yang paling sedikit bila dibandingkan dengan laju pembelajaran lain pada waktu yang sama.

\subsection{Pengujian dengan Variasi ROI}

Pada Penelitian ini dilakukan pengujian hasil perancangan pada sistem. Parameter pertama yang diuji adalah variasi ROI. Terdapat tiga variasi ROI yang akan digunakan, yaitu variasi pertama $(180 \leq \mathrm{cx}<280)$ untuk area keluar dan $(280 \leq \mathrm{cx} \leq 380)$ untuk area masuk, variasi ke-2 $(220 \leq \mathrm{cx}$ $<280)$ untuk area keluar dan $(280 \leq \mathrm{cx} \leq 340)$ untuk area masuk, dan variasi ke-3 $(250 \leq \mathrm{cx}<280)$ untuk area keluar $(280 \leq \mathrm{cx} \leq 310)$ untuk area masuk yang ditunjukan pada Gambar 5 .

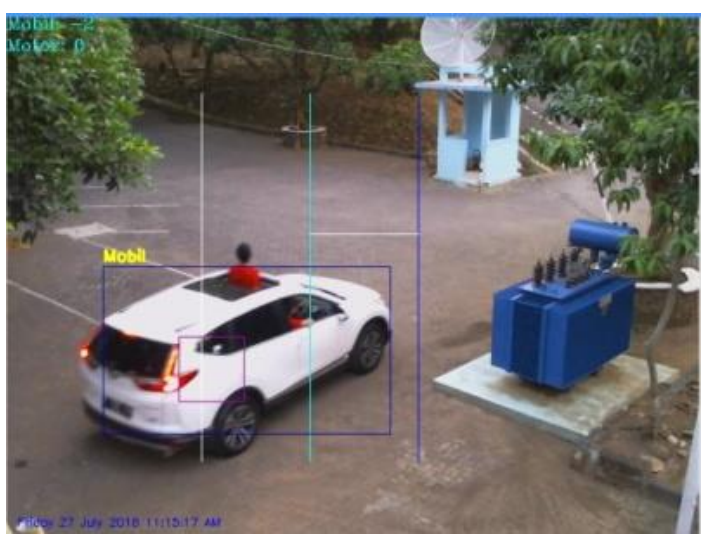

(a) 


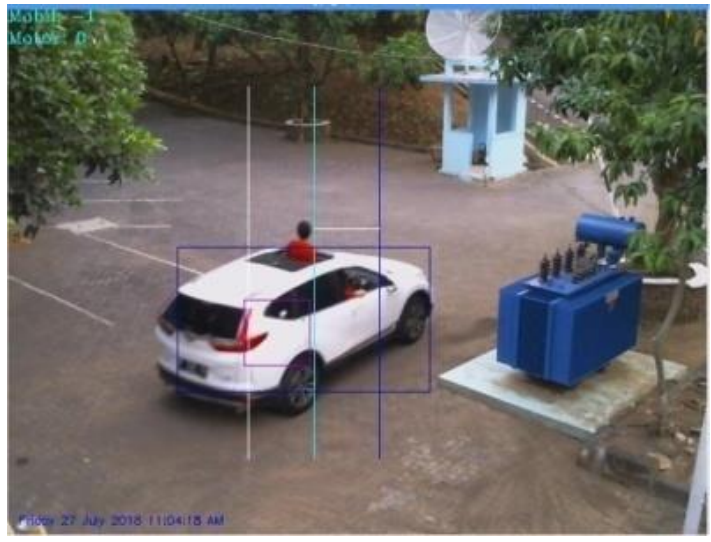

(b)

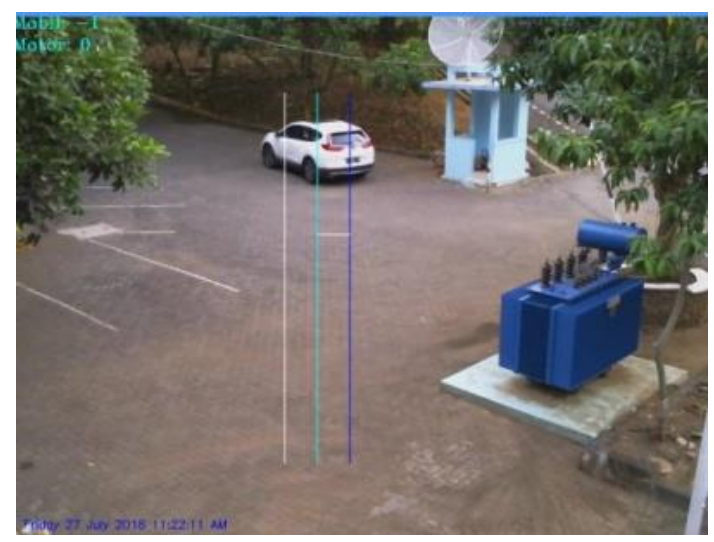

(c)

Gambar 5. (a) variasi ROI $(180 \leq \mathrm{cx}<280)$ dan $(280$ $\leq \mathbf{c x} \leq \mathbf{3 8 0}$ )

(b) variasi ROI $(220 \leq \mathrm{cx}<280)$ dan $(280$ $\leq \mathrm{cx} \leq \mathbf{3 4 0})$

(c) variasi ROI $(250 \leq \mathrm{cx}<280)$ dan $(280 \leq \mathrm{cx} \leq 310)$

Tabel 3. Pengujian data dengan variasi ROI

\begin{tabular}{|c|c|c|c|c|c|}
\hline \multicolumn{2}{|c|}{ Variasi ROI } & \multicolumn{3}{|c|}{ Perhitungan } & \multirow{2}{*}{$\begin{array}{l}\text { Keses } \\
\text { uaian }\end{array}$} \\
\hline Keluar & Masuk & + & - & $=$ & \\
\hline Manual & Manual & 1 & -1 & 0 & Sesuai \\
\hline $\begin{array}{c}180 \leq \\
\mathrm{cx}< \\
280\end{array}$ & $\begin{array}{c}280 \leq \mathrm{cx} \leq \\
380\end{array}$ & 1 & -2 & -1 & $\begin{array}{l}\text { Tidak } \\
\text { Sesuai }\end{array}$ \\
\hline $\begin{array}{c}220 \leq \\
\mathrm{cx}< \\
280\end{array}$ & $\begin{array}{c}280 \leq \mathrm{cx} \leq \\
340\end{array}$ & 1 & -1 & 0 & Sesuai \\
\hline $\begin{array}{c}250 \leq \mathrm{cx} \\
<280\end{array}$ & $\begin{array}{c}280 \leq \mathrm{cx} \leq \\
310\end{array}$ & 0 & -1 & -1 & $\begin{array}{l}\text { Tidak } \\
\text { Sesuai }\end{array}$ \\
\hline
\end{tabular}

Dari data Tabel 3. diatas dapat dilihat bahwa perhitungan jumlah kendaraan dengan menggunakan variasi ROI $180 \leq$ cx $\leq 280 \leq \mathrm{cx} \leq 380$ menghasilkan pendeteksian dengan jumlah -1 . Variasi ROI $220 \leq \mathrm{cx} \leq 280 \leq \mathrm{cx} \leq 340$ menghasilkan pendeteksian dengan jumlah 0 . Variasi ROI $250 \leq \mathrm{cx} \leq 280 \leq \mathrm{cx} \leq 310$ menghasilkan pendeteksian dengan jumlah -1 . Hasil data dari variasi ROI $220 \leq \mathrm{cx} \leq$ $280 \leq \mathrm{cx} \leq 340$ tersebut sudah sesuai dengan penjumlahan manual. Luasan ROI yang tidak terlalu lebar dan terlalu kecil akan memudahkan program dalam mendeteksi dan akan mengurangi kesalahan dalam pendeteksian program.

\subsection{Perbandingan Hasil Data}

Pengambilan data dilakukan selama 4 hari, pengujian perbandingan data dilakukan menggunakan parameter yang telah ditetapkan seperti parameter laju pembelajaran dan ROI guna membandingkan data yang diperoleh, dan juga perbandingan data yang dilakukakan pada setiap jam.

\subsubsection{Perhitungan Data Per Hari}

Hasil pengujian perbandingan data dilakukan di area parkir Departemen Teknik Elektro UNDIP. Data yang dibandingkan merupakan data perhitungan sistem pada jam 14.00 WIB. Hasil dari pengujian digunakan untuk menghitung tingkat keberhasilan dengan rumus $100 \%-\left(\frac{\text { Selisih }}{\text { Jumlah hitung manual }}\right)$. Berikut hasil pengujian
perbandingan sistem :

Tabel 4. Tabel hasil perbandingan Perhitungan Kendaraan

\begin{tabular}{cccccccc}
\hline $\begin{array}{c}\text { Hari } \\
\text { ke- }\end{array}$ & Jenis & $\begin{array}{c}\text { Sist } \\
\text { em }\end{array}$ & $\begin{array}{c}\text { Man } \\
\text { ual }\end{array}$ & \multicolumn{2}{c}{$\begin{array}{c}\text { Total } \\
\text { Kendaraan } \\
+\end{array}$} & $\begin{array}{c}\text { Sel } \\
\text { isih }\end{array}$ & Akurasi \\
\hline \multirow{2}{*}{1} & Mobil & 28 & 26 & 29 & -3 & 2 & $92,30 \%$ \\
& Motor & 63 & 56 & 67 & -11 & 7 & $87,5 \%$ \\
2 & Mobil & 15 & 16 & 23 & -8 & 1 & $93,75 \%$ \\
& Motor & 54 & 48 & 61 & -13 & 6 & $87,5 \%$ \\
3 & Mobil & 19 & 18 & 28 & -10 & 1 & $94,11 \%$ \\
& Motor & 44 & 39 & 54 & -15 & 5 & $87,17 \%$ \\
4 & Mobil & 26 & 23 & 27 & -7 & 3 & $86,95 \%$ \\
& Motor & 45 & 43 & 63 & -18 & 2 & $95,34 \%$ \\
\hline
\end{tabular}

Dari data Tabel 4. diatas terlihat bahwa selisih paling sedikit adalah 1 unit untuk kendaran mobil dan 7 unit untuk kendaran motor. Selisih tersebut didapatkan dengan menggunakan parameter ROI $220 \leq \mathrm{cx} \leq 280 \leq \mathrm{cx} \leq 340$ dengan laju pembelajaran 0.01 dan frame rate 24 . Rata-rata akurasi yang di dapat dari keseluruhan data adalah 90,57\%. Selisih kendaraan disebabkan oleh adanya tumpang tindih Bounding box kendaran dan tingginya kecepatan kendaran sehingga mempengaruhi output jumlah kendaraan. Adanya Bounding box yang tindih menyebabkan deteksi dua kendaraan atau lebih sebagai satu kendaraan atau sebaliknya satu kendaraan terdeteksi oleh dua atau lebih Bounding box. Kecepatan kendaraan juga berpengaruh karena semakin cepat kendaraan, ada kemungkinan kendaraan tidak melewati ROI. Frame video yang dihasilkan setelah proses di Raspberry Pi menyebabkan video lag sehingga ROI tidak dapat menangkap citra latar depan kendaraan. 


\subsubsection{Perhitungan Data Per Jam}

Parameter yang telah didapatkan dengan membandingkan data digunakan untuk mencari data perjamnya. Data per jam didapatkan dnegan mengambil data pada satu hari dengan durasi 08.00 sampai jam 21.00 WIB. Data yang dihitung adalah data kendaraan yang berada pada area parkir tiap dua jam. Setiap dua jam data di bandingkan antara perhitungan manual dengan sistem. Data di ambil pada tanggal 20 Juli 2018. Data yang didapat terdapat pada Tabel 5. berikut :

Tabel 5. Perbandingan Perhitungan Data Per Jam

\begin{tabular}{cccccc}
\hline Waktu & Jenis & $\begin{array}{c}\text { Siste } \\
\mathrm{m}\end{array}$ & $\begin{array}{c}\text { Manu } \\
\text { al }\end{array}$ & $\begin{array}{c}\text { Selisi } \\
\mathrm{h}\end{array}$ & Akurasi \\
\hline $08.00-$ & Mobil & 6 & 6 & 0 & $100 \%$ \\
10.00 & Motor & 24 & 25 & 1 & $96 \%$ \\
$10.00-$ & Mobil & 22 & 19 & 3 & $84,21 \%$ \\
12.00 & Motor & 43 & 38 & 5 & $86,84 \%$ \\
$12.00-$ & Mobil & 26 & 23 & 3 & $86,95 \%$ \\
14.00 & Motor & 45 & 43 & 2 & $95,34 \%$ \\
$14.00-$ & Mobil & 17 & 15 & 2 & $86,67 \%$ \\
16.00 & Motor & 39 & 35 & 4 & $88.57 \%$ \\
$16.00-$ & Mobil & 6 & 5 & 1 & $80 \%$ \\
18.00 & Motor & 30 & 28 & 2 & $92,85 \%$ \\
$18.00-$ & Mobil & 4 & 3 & 1 & $66 \%$ \\
20.00 & Motor & 16 & 11 & 5 & $54,3 \%$ \\
$20.00-$ & Mobil & 4 & 2 & 2 & - \\
21.00 & Motor & 16 & 9 & 7 & $22 \%$ \\
\hline
\end{tabular}

Data yang didapatkan memiliki selisih yang berbeda-beda. Nilai akurasi tertinggi terdapat pada jam $08.00-10.00$ yaitu $100 \%$ untuk mobil dan $96 \%$ untuk motor, sedangkan akurasi terendah pada jam $20.00-21.00$ yaitu $0 \%$ untuk mobil dan $22 \%$ untuk motor. Selisih kendaraan disebabkan kurangnya penerangan pada malam hari yang mengakibatkan program tidak dapat mendeteksi adanya kendaraan yang melintas adanya tumpang tindih bounding box kendaraan dan tingginya kecepatan kendaraan sehingga memengaruhi output jumlah kendaraan. Keakuratan data juga dipengaruhi oleh komputasi citra Raspberry Pi. Komputasi pengolahan citra pada Raspberry $\mathrm{Pi}$ tidak memiliki kecepatan yang tinggi karena spesifikasinya, sehingga terdapat delay dan lag.

\section{Kesimpulan}

Berdasarkan pengujian yang telah dilakukan, sistem penghitung trafik kendaraan dapat berjalan dengan optimal menggunakan laju pembelajaran 0.01 dan ROI $220 \leq \mathrm{cx} \leq$ $280 \leq \mathrm{cx} \leq 340$ pada Raspbery Pi 3. Penerapan deteksi gerak dengan algoritma gaussian mixture model pada sistem trafik kendaraan mulai dari proses deteksi gerak, klasifikasi kendaraan penghitung kendaraan, log, dan sinkronisasi data telah berhasil berjalan dengan baik. Penerimaan data berjalan dengan lancar di basis data dstp.puskom.undip.ac.id. Keakuratan data dipengaruhi oleh komputasi citra Raspberry Pi, pengaruh lain adalah adanya tumpang tindih bounding box kendaraan dan kecepatan kendaraan juga disebabkan kondisi cahaya yang kurang memadai saat malam hari menyebabkan tidak adanya kendaraan yang terdeteksi saat melintas. Rata-rata akurasi tingkat keberhasilan pada pengujian data per hari adalah $90,57 \%$, sedangkan pada pengujian per jam akurasi tertinggi terdapat pada jam $08.00-10.00$ yaitu $100 \%$ untuk mobil dan $96 \%$ untuk motor.

\section{Referensi}

[1] S. Harso, Pengenalan dan Pengembangan Smart City, no. April. LPIK ITB dan Smart City Initiatives Forum, 2008.

[2] F. A. Surur, "Analisis Trafik Kendaraan Dengan Metode Background Subraction di Kampus UNDIP Berbasis Internet Of Things (IoT),"pp. 4-9, 2017.

[3] D. Li, B. Liang, and W. Zhang, "Real-time moving vehicle detection, tracking, and counting system implemented with OpenCV," ICIST 2014 - Proc. 2014 4th IEEE Int. Conf. Inf. Sci. Technol., pp. 631634, 2014.

[4] W. J. Wang and M. Gao, "Vehicle Detection and Counting in Traffic Video Based on OpenCV," Appl. Mech. Mater., vol. 361-363, pp. 2232-2235, 2013.

[5] M. Harry Bintang, “Aplikasi Deteksi Gerak Pada Kamera Keamanan Menggunakan Metode Background Subtraction dengan Algoritma Gaussian Mixture Model,” pp. 117-125, 2017.

[6] S. Shah, Learning Raspberry Pi. Packt Publishing Ltd, 2015.

[7] OpenCV, "OpenCV library." [Online]. Available: http://opencv.org/. [Accessed: 09-Apr-2017].

[8] J. Gubbi, R. Buyya, S. Marusic, and M. Palaniswami, "Internet of Things ( IoT ): A vision, architectural elements , and future directions," Futur. Gener. Comput. Syst., vol. 29, no. 7, pp. 1645-1660, 2013. 